\title{
The Reflection of the Observation of English Classes
}

\section{Wanyun He}

Department of Foreign Studies, Yangtze University College of Arts and Science, Jingzhou, Hubei, China

\begin{abstract}
Classroom observation is of essential significance for teaching practice and language education. Based on the observation experiences of English classes, this article explores classroom observation from six aspects, such as lesson structures, classroom management strategies, types of teaching activities, teaching strategies, teachers' use of materials and teachers' use of language.
\end{abstract}

Key words: classroom observation; effective teaching; language education

\section{Introduction}

Classroom observation plays a significant role in practice teaching, especially for the novice teachers. A whole view of classroom practice could be achieved by the observation and observation also enable us to know how to realize teaching goals within a realistic context. Classroom observation could not only be treated as the assessing tool and evaluation approach of teacher practice, but also a good approach to monitor and mentor novice teachers (Martinez, F., 2016). Luckily, as the new teacher in the School of Foreign Languages, plenty of observation opportunities are available including listening, fast reading, academic writing etc. It is a great chance to observe how to apply various teaching methods, techniques and skills in the specific environment. The class itself hardly provides clear clues for observers to observe. As Richards \& Farrell (2011) noted, teaching is a complex and dynamic activity, and it is not possible to observe all of them. Thus this article would only reflect from six aspects which are not isolated, and all the competences need to be combined systematically.

\section{Six Aspects of Classroom Observation}

\subsection{Lesson structures}

Effective teaching guarantees students' learning outcomes and offers help to facilitate their learning (Farrell, 2015). A clear structure makes students easy to follow. Pacing a class to let it become nearly seamless needs expertise and practice. Below is an excellent example. One of the classes opened with greeting to cheer students up, which made each student feel important and set a positive tone to the class. Next 15 minutes was to illustrate the test instruction including location, marking rules and test content. And the next 15 minutes was for correcting assignment, followed by a 30 minutes' reading task. Then, the teacher took 20 minutes to explain how to take margin notes, with first paragraph of homework as the example. The class ended with the reminder of homework and a final note of the block area in the building. A lesson structure maps out the teaching and learning occur in class with a concise and organized structure. If a lesson is well

Copyright $(\mathcal{C} 2021$ by author(s) and Frontier Scientific Research Publishing Inc.

This work is licensed under the Creative Commons Attribution International License (CC BY 4.0).

$\mathrm{http} / /$ creativecommons.org/licenses/by/4.0/ 
designed, even the most inexperienced teacher could make the whole lesson effective. Thus, for the novice teacher, it is especially helpful to study the lesson structure from the observation.

\subsection{Classroom management strategies}

Classroom management is the actions and strategies teachers use to solve the problem of order in classrooms, covering the areas of setting up groups, arranging seats and maintaining order to ensure that students are well involved in the learning atmosphere. The purpose of the management is not to control students' behavior, but to direct the students to follow the instruction. Setting up groups is more than simply dividing students into small groups. In one of the observations, the teacher assigned the groups directly and asked them to sit together. The decision came from the fact that students in this class usually only sit with their friends which led to the social isolation. Another observation example is about the rules. Clear explanations as well as the rehearsal of the rules are usually provided by the teachers. In one of observations, the students tried to speak mandarins in the group discussion. When teacher noticed this, she walked to that group and stopped them, and repeated the rule of only English in the classroom.

\subsection{Types of teaching activities}

Classroom management strategies are noticeably reflected in the classroom activities. Classroom activities in teaching process need to be stressed, which could help the learners gain learning competencies. Akan, D. (2013) also suggested that students presume they can achieve a better learning outcomes with the classroom activities and they are more interested in the classes where there are activities. Brainstorming is a typical whole-class activity which benefits students' participation and involvement. An representative example in the observation is reviewing words learned in previous classes. Pair activities facilitates teachers to accelerate the pace of the class, monitoring the classroom, as well as narrowing the comprehension gap between students who have different language proficiency. There are also various individual activities occurring in the observations such as pre-reading and listening practice.

\subsection{Teaching strategies}

Chinese is significantly different with English in characters, grammars and pronunciations because they belong to different language families, leading to a great challenge when native Mandarin Chinese students are learning English. In this situation, the good selection of teaching strategies matters a lot. Scaffolding proposed by Vygotsky can not only engages the learners through pushing them form new knowledge, but also largely minimize the level of frustration. In one of the observations, when the teacher processed the crosswords activity, she listed out words as the hints to help students complete the task. Narrative is also powerful. Stories allow the ability to master the ownership of their behavior, actions and thoughts, realizing what is going on in their lives, and contributing to the personal change and growth. In one listening class, the video referred lemon and lime. The teacher shared her life story to differentiate the two citrus fruits.

\subsection{Teachers' use of materials}

Teachers adopt various teaching strategies and activities on the class to satisfy the needs of different types of classes. In this way, teaching materials also need to be well chosen. In the observations, there are various materials applied in the classroom with their unique strength. The textbook is always the priority for most of the teachers, and the lexical coverage matters. According to Laufer and Nation's previous studies, we can conclude that students can understand the article when they reach the lexical coverage of $95 \%$. But if they want to gain an adequate comprehension, they need to increase their vocabulary size to $98 \%$. Textbook is always the mainstream, but the online resources is also indispensable, especially with the rapid development of hybrid courses. The resources from online newspaper, magazine or website are good supplement, which are available at all levels ranging from pre-school to post-doctoral. Individual user need to evaluate the resource or information to guarantee its credibility and reliability due to the inefficiency of regulation for quality or accuracy. 


\subsection{Teachers' use of language}

Appropriate language can create a positive learning atmosphere and continually giving students confidence. The subtle differences in language may make a big difference. Thus, how to apply suitable language in the instruction, explanation and feedback is a significant aspect to reflect. Language can comfort students' mood and create them a positive atmosphere. In one observation, the instructor uses a series of sentences such as "No question is silly.", "Free to email me at any time." to reduce students' anxious to ask questions. Various feedback techniques used on the class also gives me some enlightenment. For example, in one class, the teacher did not directly point out wrong sentence and fix it. Instead, she reminded students to recall the grammar points they have learned in previous classes.

\section{Conclusions}

The observation enables us to understand how to conduct an effective lesson and provides good opportunities to explore different teaching styles. Observed teacher, observation and post-observation debriefing are three essential components. The focus is better to be identified before the observation. It could not only place the observed teacher in a primary place to facilitate his development, also offer a clear focus and clue for the observer. Classroom is complex and complicated which means that a large quantity of data and descriptive details collected during observation would contribute to a holistic picture of the focused area. A collaborative post-debriefing in terms of the focus is also significant, including examination of purpose of the observation, highlights and deficiencies of teaching practice, decent suggestions etc.

\section{Conflicts of Interest}

The author declares no conflicts of interest regarding the publication of this paper.

\section{References}

[1] Farrell, T.S.C. (2015). It's not who you are! It's how you teach! Critical Competencies Associated with Effective Teaching. RELC Journal, 46(01):79-88.

[2] Richards, J.C., Farrell, T.S.C. (2011). Practice Teaching: A Reflective Approach. Cambridge: Cambridge University Press.

[3] Martinez, F., Taut, S., Schaaf, K. (2016). Classroom Observation for Evaluating and Improving Teaching: An International Perspective. Studies in Educational Evaluation, (49):15-29.

[4] AKAN, D., BASAR, M. (2013). The Effect of the Classroom Activities on Classroom Management in the Teaching-learning Process: The Case of Uşak City. Mevlana International Journal of Education, 3(04):147-165.

[5] Grimm, E.D., Kaufman, T., Doty, D. (2014). Rethinking Classroom Observation. Educational Leadership, 71(08): 24-29. 